\title{
Study on Efficiency Model of Gasoline Engine Used by Hybrid Electrical Vehicle
}

\author{
Jinguang Liang \\ Department of Machinery and Power Engineering, Yingkou Institute of Technology, Yingkou 115000, China
}

Keywords: hybrid electrical vehicle; gasoline engine; control; efficiency model

\begin{abstract}
It is a difficult problem to precisely control a gasoline engine used by a Hybrid Electrical Vehicle (HEV) operating in high efficient states because of the engine's uncertain fuel consumption characteristics. The problem can be resolved by setting up an efficiency model for the engine to implement feedback control. Based on theoretical analysis and a large number of experimental investigations on a LJ491QE1 and a 4G18-AA gasoline engine, the theory was presented that using equivalent air exchange loss or experience equivalent air exchange loss as a general efficiency model for naturally aspirated port fuel injection gasoline engines used by the HEV can determine the dynamically varied engine efficient working region. The experience equivalent air exchange loss which only used two parameters of an intake air pressure and an exhaust gases pressure can determine the dynamically varied high efficient working region of the engines and it has a better responsiveness than the equivalent air exchange loss.
\end{abstract}

\section{Introduction}

It is one of the major factors for a HEV to achieve energy saving and emission reduction that the engine always operates in high efficient states. However, dynamic changes of the engine's external environment conditions, such as the coolant temperature, the atmospheric pressure, the air humidity, etc.; and the engine's own conditions, such as the degree of mechanical wear, the carbon deposited in the combustion chamber, the impurities deposited in the fuel system, etc., lead to uncertain fuel consumption characteristics of the engine ${ }^{[1]}$, it is difficult to control the HEV engine operating in high efficient states accurately all the time. Nowadays the correction parameters obtained by tests are usually used to determine the dynamically changed high efficient states of the $\mathrm{HEV}$ engine, and because of the lack of common theoretical basis the correction parameters cannot be shared by different type engines. Furthermore, a large number of tests were needed for obtaining the correction parameters, the correction parameters cannot automatically adapt to the change of the engine's own conditions and the accuracy of the tests need to be ensured, for these reasons, a great deal of investment and long period was needed for a HEV research and development, and the control accuracy of the HEV engine cannot be guaranteed all the time.
At present, there is no relevant research report about how to determine the dynamically changed high efficient working states of the HEV engine, which make the related research more difficult. In order to solve the problem that exists in the HEV engine research and development, a HEV engine efficiency model that considers the dynamic changes of the engine's external environment and the engine's own conditions is needed to be established and the purpose of accurately control the HEV engines can be achieved.

\section{Fundamental theory}

Based on an efficiency model using the engine's working state parameters, which is established by the means of researching on the regularity between the engine's effective thermal efficiency and its working state parameters, the engine can be controlled operating in high efficient working states without the influence of the engine's external environment and its own conditions.

\subsection{Engine efficiency model.}

A model is a form of expression of a system, a process, a concept or thing which is studied. An analogy model refers that if independent variables of the system in different area of physics obey the same laws, a match or an analogy model of completely different physical meaning can be built on the basis of same laws. The engine efficiency also named as effective thermal efficiency is a ratio between the effective work of the actual cycle and the heat consumed to obtain the effective work. The effective thermal efficiency is inversely proportional to the engine effective fuel consumption (also named as engine specific fuel consumption), and they are important indicators to measure the engine economic performance. Engine specific fuel consumption is usually used to visually represent the change rules of the engine efficiency instead of the effective thermal efficiency in the practical studies.

The engine efficiency model should have the following characteristics that the independent variables of the model are the parameters of the engine work status (such as the temperature, the pressure, etc.), the value of the model and the value of the effective thermal efficiency or effective specific fuel consumption should have the same change rule under steady state load characteristic test, the model value can reflect the impact on the engine efficiency by the changes of external environment conditions and the engine itself. In other words, the engine efficiency model should be a function of its 
working state parameters, external environment and the engine's own conditions, and the change rules of the model value should be same as the change rules of the effective thermal efficiency or effective specific fuel consumption which dynamically change along with the external environment conditions and the engine itself conditions under load characteristic test.

\subsection{The optimal speed characteristic curve and the efficient workspace}

The optimal speed characteristic curve is defined as a curve linked by every minimum effective specific fuel consumption point of all load characteristic curves under the same environment conditions and the engine itself conditions.

Based on the universal characteristic experiments of a LJ491QE1 and a DA4G18-AA gasoline engine, the effective specific fuel consumption of a gasoline engine $g_{e}$ usually vary from $250 \mathrm{~g} /(\mathrm{kW} \cdot \mathrm{h})$ to $750 \mathrm{~g} /(\mathrm{kW} \cdot \mathrm{h})$ under load range $10 \%$ $100 \%$ of the load characteristic at different engine speeds. In order to quantify the engine's better economical working area, the efficient workspace at an engine speed is defined as a load range in load characteristic curves which neighbourhood radius is 5 effective specific fuel consumption units and take the minimum effective specific fuel consumption point as the centre of the neighbourhood. That is, the efficient workspace is an engine working range under the load characteristic. The neighbourhood radius of the efficient workspace corresponds to $2 \%$ of the gasoline engine's absolute minimum specific fuel consumption $g_{\text {emin }} 250 \mathrm{~g} /(\mathrm{kW} \cdot \mathrm{h})$, so the efficient workspace can be taken as the minimum effective specific fuel consumption point at the same engine speed, and the engine operating range contained by efficient workspace at all engine speeds can be approximately taken as the optimal speed characteristic curve. The power follower mode and the switch mode of the engine used by Series Hybrid Electric Vehicle correspond to the optimal speed characteristic curve and the absolute minimum specific fuel consumption point $g_{\text {emin }}$ respectively.

\subsection{Combustion efficiency of gasoline}

Combustion efficiency of gasoline refers to the ratio between the total quantity of heat actually released and theoretically released by the fuel combustion. Usually, combustion efficiency $\eta_{c b}$ is used to measure the degree of fuel's incomplete combustion. In order to simplify the theoretical analysis of gasoline combustion efficiency, it is assumed that the gasoline is completely oxidized when instantaneous excess air coefficient $\lambda^{[2]}$ of the mixed gas is greater than 1 , combustion efficiency of the gasoline is $100 \%$, under the gasoline engine steady state conditions; and when the $\lambda$ is less than 1 , caused by a lack of air, the oxygen in the air oxidize the hydrogen in the gasoline first, and then oxidize the carbon in the gasoline into carbon monoxide, if there is some oxygen left the carbon monoxide would be oxidized further into carbon dioxide. Usually, the heat value loss $\Delta H_{u}(\mathrm{~kJ} / \mathrm{kg})$, caused by $\lambda$ less than 1 , because of the gasoline's incomplete combustion can be calculated by the following formula ${ }^{[3]}$ :

$$
\Delta \mathrm{H}_{\mathrm{u}} \approx 58000(1-\alpha)
$$

Where the $\alpha$ is the excess air coefficient ${ }^{[3]}$. The low heat value of gasoline is approximately $43960 \mathrm{~kJ} / \mathrm{kg}$, and the theoretical calculation formula of the gasoline combustion efficiency can be expressed as:

$$
\eta_{\mathrm{cb}}=\frac{43960-58000(1-\alpha)}{43960}
$$

When the $\lambda$ is greater than 1 , the excess air coefficient $\alpha$ assigns 1 .

\subsection{Equivalent air change loss}

During the course of actual suction and exhaust stroke of the naturally aspirated engine, gases flow through the air filter, throttle, intake pipe, intake valve, exhaust valve, exhaust pipe, three way catalytic converter and muffler, etc., where the frictional resistance loss and local resistance loss are generated, forming suction power loss and forced exhaust power loss of the piston. In addition, in order to guarantee the engine's good performance, the exhaust valve needs to be opened before the dead centre of expansion stroke, and more exhaust gases can be exhausted, cylinder pressure can be reduced, exhaust power of the forced exhaust stage can also be reduced, but it also reduce the useful work area on the indicator diagram, which named as expansion loss. The suction power loss is named as intake loss. The sum of the forced exhaust power loss and expansion loss is named as exhaust losses and the sum of intake and exhaust loss is named as air exchange loss. According to the energy equation for Newtonian ideal airflow ${ }^{[1]}$ :

$$
\mathrm{e}_{1-0}=\frac{\mathrm{p}_{1}^{*}-\mathrm{p}_{\mathrm{a}}}{\rho_{1}}+\mathrm{c}_{\mathrm{v}}\left(\mathrm{T}_{1}^{*}-\mathrm{T}_{0}\right)
$$

Where the $e_{1-0}$ is the airflow energy per unit mass, $p_{l}{ }^{*}$ is the total pressure of the airflow, $T_{l}{ }^{*}$ is the total temperature of the airflow, $\rho_{l}$ is the density of the airflow, $c_{v}$ is the specific heat at constant volume of the airflow, $p_{a}$ is the absolute pressure of the outside environment, $T_{0}$ is the thermodynamic temperature of the outside environment. So, the intake loss of per unit mass gases $e_{i}$ is ${ }^{[1]}$ :

$$
e_{i}=\frac{p_{v i}}{\rho_{i}}
$$

Where the $p_{v i}$ is the vacuum degree of the intake gases, $\rho_{i}$ is the density of the intake gases. And the exhaust loss of per unit mass gases $e_{e}$ is ${ }^{[1]}$ :

$$
\mathrm{e}_{\mathrm{e}}=\frac{\mathrm{p}_{\text {gage }}}{\rho_{\mathrm{e}}}
$$

Where the $p_{\text {gage }}$ is the gauge pressure of the exhaust gases, $\rho_{e}$ is the density of the exhaust gases. Then the equivalent air change loss of per unit mass gases $e_{q r}$, which is corrected to the same combustion efficiency level, is ${ }^{[1]}$ :

$$
\mathrm{e}_{\mathrm{qr}}=\frac{\mathrm{e}_{\mathrm{i}}+\mathrm{e}_{\mathrm{e}}}{\eta_{\mathrm{cb}}}=\frac{\mathrm{p}_{\mathrm{vi}}}{\rho_{\mathrm{i}} \eta_{\mathrm{cb}}}+\frac{\mathrm{p}_{\text {gage }}}{\rho_{\mathrm{e}} \eta_{\mathrm{cb}}}
$$




\section{Test}

Figure 1 shows the layout of the engine air change loss test bench. The testes were carried out to a naturally aspirated port injection LJ491QE1 gasoline engine. The primary parameters of the engine are listed as follows: the displacement is 2.237 $\mathrm{L}$, the compression ratio is 8.8 , the maximum torque (rotate speed) is $190 \mathrm{~N} \cdot \mathrm{m}(2400-2800 \mathrm{r} / \mathrm{min})$, and the maximum power (rotate speed) is $75.0 \mathrm{~kW}(4600 \mathrm{r} / \mathrm{min})$. The sensors series for collecting the engine working state parameters include: the coolant temperature sensor, the intake air temperature \& pressure sensor, the exhaust air temperature sensor and the exhaust air pressure sensor, etc.

\subsection{Test of equivalent air change loss}

The engine air change loss tests were designed to study the change rules of the equivalent air change loss $e_{q r}$ and the effective specific fuel consumption $g_{e}$ vary along with the engine load under the load characteristics. The engine speeds of the load characteristic tests were chosen as $1800 \mathrm{r} / \mathrm{min}$, $2200 \mathrm{r} / \mathrm{min}, 3800 \mathrm{r} / \mathrm{min}$ and $4200 \mathrm{r} / \mathrm{min}$. The tests results indicated that under the LJ491QE1 engine load characteristic, the equivalent air change loss $e_{q r}$ and the effective specific fuel consumption $g_{e}$ had the same change rules vary along with the engine load under the load characteristics, and the engine working state of the minimum equivalent air change loss was in the efficient workspace. Figure 2 shows the curve of the equivalent air change loss $e_{q r}$ and the effective specific fuel consumption $g_{e}$ vary along with the engine load percentages $l_{p}$ under the $3800 \mathrm{r} / \mathrm{min}$ load characteristics test.

The load interval of the above load characteristics tests were $10 \%$. In order to confirm whether there is accurate corresponding relationship between the equivalent air change $\operatorname{loss} e_{q r}$ and the effective specific fuel consumption $g_{e}$ of the naturally aspirated port injection gasoline engine under the load characteristics, small load interval characteristics tests were carried out to the LJ491QE1 engine and the engine speeds of the tests were chosen as $2200 \mathrm{r} / \mathrm{min}, 3000 \mathrm{r} / \mathrm{min}$, $3800 \mathrm{r} / \mathrm{min}$ and $4200 \mathrm{r} / \mathrm{min}$. The load interval $5 \mathrm{~N} \cdot \mathrm{m}$ was chosen at engine working state of high load (where the engine load percentages $l_{p}$ is greater than $66 \%{ }^{[1]}$ and the engine working state of absolute minimum specific fuel consumption $g_{\text {emin }}$ exists), and the load interval $10 \%$ was still chosen at the engine working state of medium and small load. The tests results also indicated that under the LJ491QE1 engine load characteristic, the equivalent air change loss $e_{q r}$ and the effective specific fuel consumption $g_{e}$ had the same change rules vary along with the engine load, and the engine working state of the minimum equivalent air change loss was in the efficient workspace. Figure 3 shows the curves of the equivalent air change loss $e_{q r}$ and the effective specific fuel consumption $g_{e}$ vary along with the engine load percentages $l_{p}$ under the $3800 \mathrm{r} / \mathrm{min}$ small load interval characteristics test.

In order to exclude it was the specific structure of the engine that led to the above test results, some engine part structure related to the equivalent air change loss $e_{q r}$ should be changed and then the small load interval characteristics tests should be carried out. The test was named as changing structure small load interval characteristics test. Figure 4 shows that a butterfly throttle valve was installed at the end of the LJ491QE1 engine's exhaust pipe and the equivalent air change loss $e_{q r}$ could be varied by changing the degree of valve.

The changing structure small load interval characteristics tests were carried out to the LJ491QE1 engine. The engine speed was chosen as $1600 \mathrm{r} / \mathrm{min}$, the load interval $5 \mathrm{~N} \cdot \mathrm{m}$ was chosen at engine working state of high load and the load interval $10 \%$ was still chosen at engine working state of medium and small load. The angle of the exhaust butterfly throttle valve was chosen as 90 degrees (wide open), 80 degrees, 70 degrees, 60 degrees, 50 degrees, 40 degrees and 30 degrees. When the angle was chosen as 20 degrees or smaller, the engine operated unstably, fuel consumption, coolant temperature and noise increase sharply, cylinder knocking came out. The tests results indicated that under the LJ491QE1 engine changing structure small load interval characteristics tests, the equivalent air change loss $e_{q r}$ and the effective specific fuel consumption $g_{e}$ had the same change rules vary along with the engine load, and the engine working state of the minimum equivalent air change loss was in the efficient workspace. Figure 5 shows the curves of the equivalent air change loss $e_{q r}$ and the effective specific fuel consumption $g_{e}$ and the exhaust gauge pressure $p_{\text {gage }}$ vary along with the engine load percentages $l_{p}$ under the $1600 \mathrm{r} / \mathrm{min}$ changing structure small load interval characteristics tests.

\subsection{Test of experience equivalent air change loss}

All data of the above test to the LJ491QE1 engine show that the value of $\left(p_{\text {gage }}^{2}+p_{v i}^{2}\right) / \eta_{c b}$ had the same change rules vary along with the engine load, and the engine was in its efficient workspace when the $\left(p_{\text {gauge }}^{2}+p_{v i}^{2}\right) / \eta_{c b}$ achieved the minimum value. The formula $E_{q r}=\left(p_{g a g e}^{2}+p_{v i}^{2}\right) / \eta_{c b}$ was named as experience equivalent air exchange loss. Figure 6 shows the curves of the equivalent air change loss $E_{q r}$ and the effective specific fuel consumption $g_{e}$ vary along with the engine torque $T_{t q}$ under the LJ491QE1's $3000 \mathrm{r} / \mathrm{min}$ load characteristics test. The curves shows that under the load characteristic, the equivalent air change loss $E_{q r}$ and the effective specific fuel consumption $g_{e}$ had the same change rules vary along with the engine torque $T_{t q}$, and the effective specific fuel consumption $g_{e}$ achieved its minimum value $g_{\text {emin }}$ when the experience equivalent air change loss was at its minimum value.

In order to confirm whether there is accurate corresponding relationship between the experience equivalent air change loss $E_{q r}$ and the effective specific fuel consumption $g_{e}$ of naturally aspirated port injection gasoline engine under the load characteristics, verification tests were carried out to a naturally aspirated port injection 4G18-AA gasoline engine and the engine speeds of the tests were chosen as $2600 \mathrm{r} / \mathrm{min}$, $3400 \mathrm{r} / \mathrm{min}, 3800 \mathrm{r} / \mathrm{min}$ and $4500 \mathrm{r} / \mathrm{min}$. The primary parameters of the engine are listed as follows: the displacement is $1.584 \mathrm{~L}$, the compression ratio is 10.0 , and the maximum torque (rotate speed) is $138 \mathrm{~N} \cdot \mathrm{m}(4500 \mathrm{r} / \mathrm{min})$, maximum power (rotate speed) $79.3 \mathrm{~kW}(6000 \mathrm{r} / \mathrm{min})$. 
The tests results indicated that under the 4G18-AA engine load characteristics tests, the experience equivalent air change loss $E_{q r}$ and the effective specific fuel consumption $g_{e}$ had the same change rules vary along with the engine load, and the engine working state of the minimum experience equivalent air change loss was in the engine efficient workspace. Figure 7 shows the curves of the experience equivalent air change loss $E_{q r}$ and the effective specific fuel consumption $g_{e}$ vary along with the engine load percentages $l_{p}$ under the 4G18-AA engine $2600 \mathrm{r} / \mathrm{min}$ load characteristics tests.

Similar to the above changing structure small load interval characteristics tests to the LJ491QE1 gasoline engine, the changing structure load characteristics tests were carried out to the 4G18-AA engine by means of changing the diameter of the throttle from $50 \mathrm{~mm}$ to $60 \mathrm{~mm}$, and the engine speeds of the tests were chosen as $2600 \mathrm{r} / \mathrm{min}, 3000 \mathrm{r} / \mathrm{min}, 3600 \mathrm{r} / \mathrm{min}$ and $4000 \mathrm{r} / \mathrm{min}$. The tests results indicated that under the 4G18-AA engine changing structure load characteristics tests, the experience equivalent air change loss $E_{q r}$ and the effective specific fuel consumption $g_{e}$ had the same change rules vary along with the engine load, and the engine working state of the minimum experience equivalent air change loss was in the engine efficient workspace. Figure 8 shows the curves of the experience equivalent air change loss $E_{q r}$ and the effective specific fuel consumption $\mathrm{g}_{\mathrm{e}}$ had the same change rules vary along with the engine load percentages $l_{p}$ under the 4G18-AA engine $3600 \mathrm{r} / \mathrm{min}$ changing structure load characteristics tests.

\section{Efficiency model of gasoline engine used by HEV}

Above theoretical analysis and a large number of tests on the LJ491QE1 and 4G18-AA engine indicated that the experience equivalent air change loss $E_{q r}$ and the equivalent air change loss $e_{q r}$ had the same change rules vary along with the effective specific fuel consumption $g_{e}$ under the naturally aspirated port injection gasoline engine load characteristic. The experience equivalent air change loss $E_{q r}$ and the equivalent air change loss $e_{q r}$ can be used as a general efficiency model of a naturally aspirated port injection gasoline engine to accurately control the engine operating in its efficient workspace by feedback way.

Compare with the equivalent air change loss $e_{q r}$, calculating the experience equivalent air change loss $E_{q r}$ only need two parameters of intake air pressure and exhaust gases pressure, need not the parameter of exhaust gases temperature. Intake air pressure and exhaust gases pressure have better transient response than the exhaust gases temperature, so using the experience equivalent air change loss $E_{q r}$ as the efficiency model of gasoline engine used by HEV is more suitable than the equivalent air change loss $e_{q r}$. The electronic control model of HEV can only use the working parameter of intake air pressure and exhaust gases pressure of the engine to accurately control the engine operating in its efficient workspace by feedback way with the parameter of the engine fuel consumption etc. unknown.

It's important to note that using the experience equivalent air change loss $E_{q r}$ to feedback control the naturally aspirated port injection gasoline engine used by HEV is on the basis of the same changing rules between the experience equivalent air change loss $E_{q r}$ and the effective specific fuel consumption $g_{e}$, as for whether the $E_{q r}$ and the $g_{e}$ have the same rates of change is not important for the engineering application. It will need a large number of verified tests on same kind and different type engine to prove that the experience equivalent air change loss $E_{q r}$ and the equivalent air change loss $e_{q r}$ can be used as a general efficiency model of naturally aspirated port injection gasoline engine used by HEV for feedback control in the future.

\section{Summary and conclusions}

The concepts of efficiency model of gasoline engine used by $\mathrm{HEV}$, the optimal speed characteristic curve, the efficient workspace, the equivalent air change loss and the experience equivalent air change loss were defined. The experience equivalent air change loss $E_{q r}$ and the equivalent air change loss $e_{q r}$ were verified to be efficiency models for the HEV control by a large number of tests to the LJ491QE1 and 4G18-AA gasoline engine, and it is significant for researching whether the $E_{q r}$ and $e_{q r}$ can be used as a universal efficiency model of the naturally aspirated port injection gasoline engine used by HEV.

\section{Acknowledgements}

This work is supported by Liaoning Provincial Committee of Education General Research Projects (No.L2014594), all support is gratefully acknowledged.

\section{References}

[1] Liang Jinguang, Study on Efficiency Model of Gasoline Engine Used by Hybrid Electrical Vehicle, Dissertations of Jilin University, 2010.

[2] Zhou Longbao, Internal Combustion Engine, Beijing: China Machine Press, 2005.

[3] Jiang Deming, Principles of Internal Combustion Engine, Beijing: China Machine Press, 1988.

[4] China State Bureau of Quality and Technical Supervision (CSBTS), GB 18351-2001 Ethanol gasoline for motor vehicles, Beijing: CSBTS, 2001.

[5] Bosch Company (Germany), Gasoline Engine Management, translated by Wu Sen, Beijing: Beijing Institute Technology Press, 2009. 


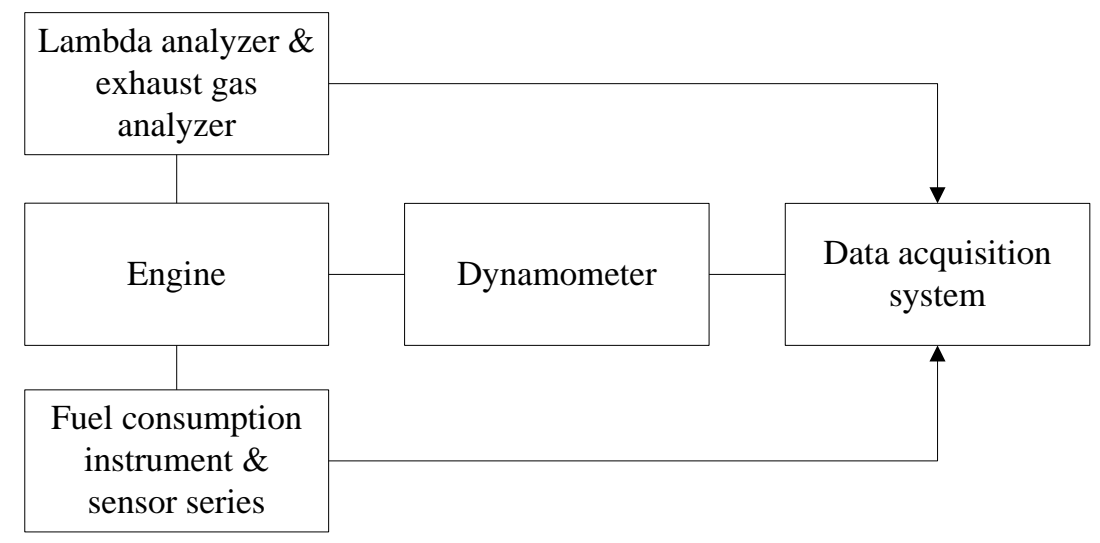

Figure 1: Layout of the engine test bench

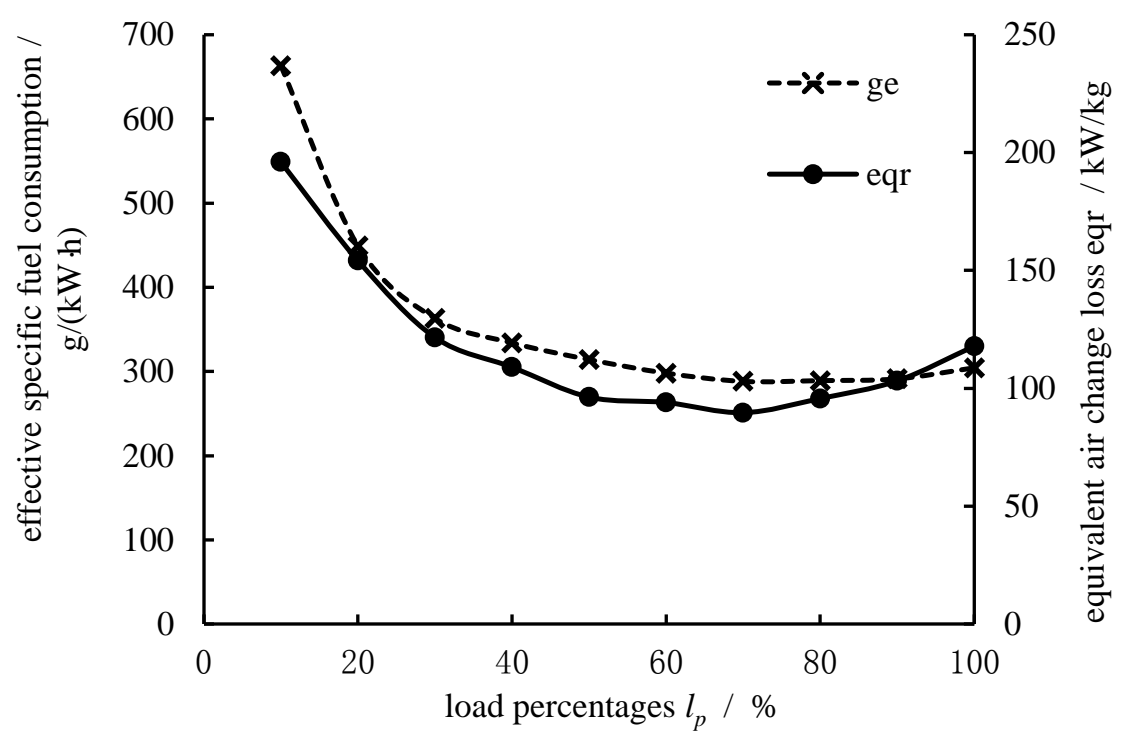

Figure 2: Curves of $e_{q r}$ and $g_{e}$ vary along with $l_{p}$ under the LJ491QE1 engine $3800 \mathrm{r} / \mathrm{min}$ load characteristics

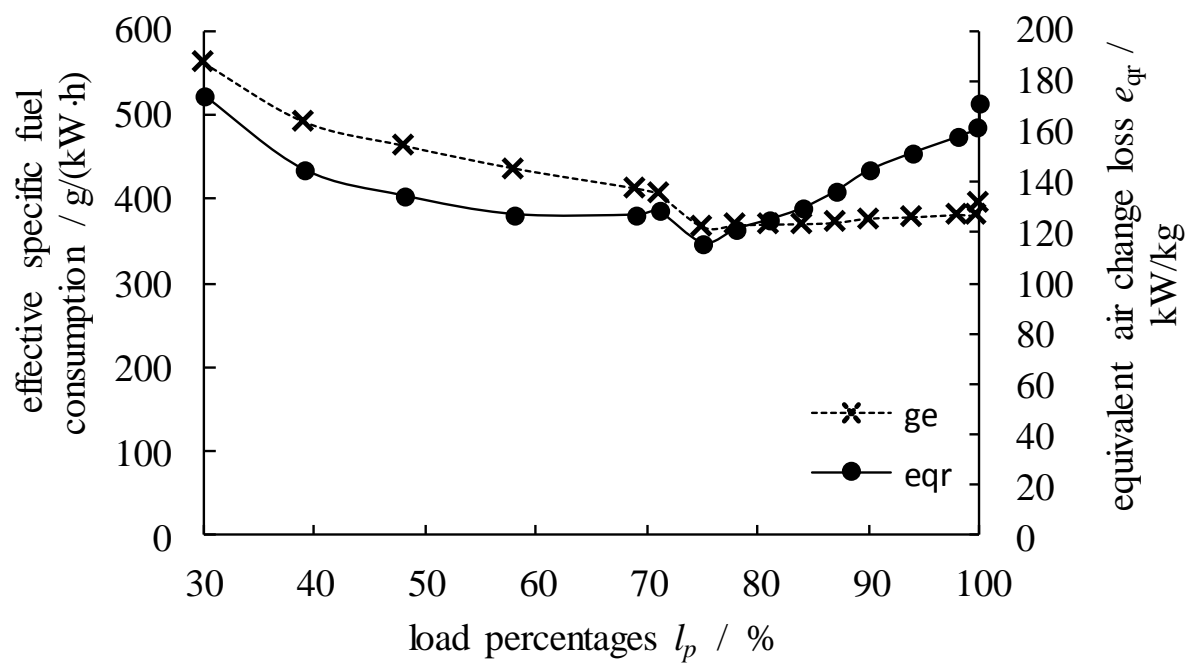

Figure 3: Curves of $e_{q r}$ and $g_{e}$ vary with $l_{p}$ under the LJ491QE1 engine $3800 \mathrm{r} / \mathrm{min}$ small load interval characteristics 


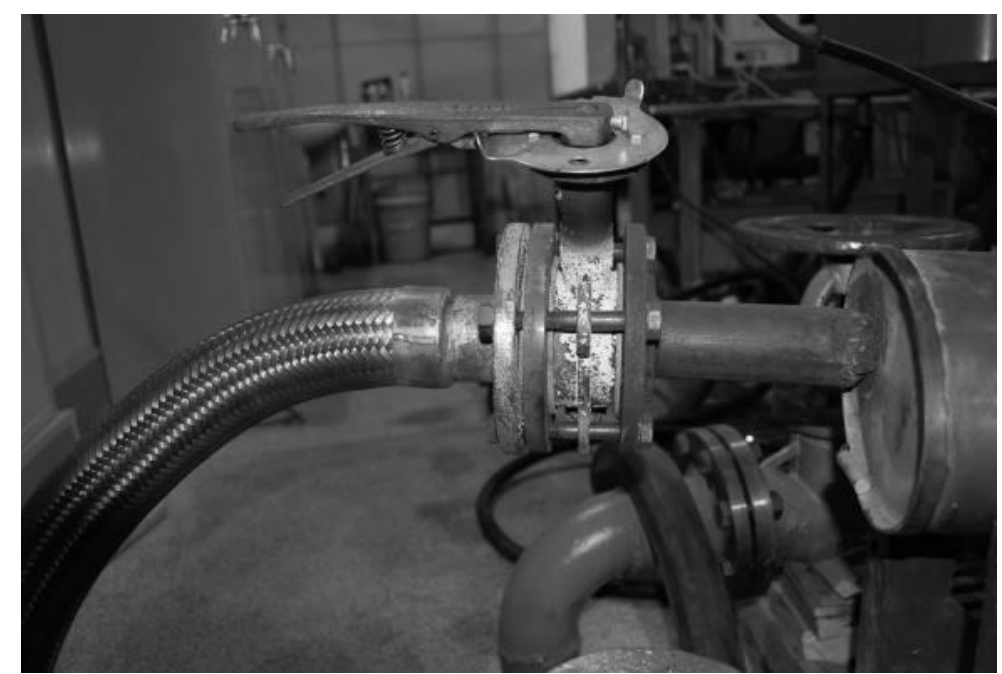

Figure 4: Exhaust butterfly throttle valve of the LJ491QE1 engine

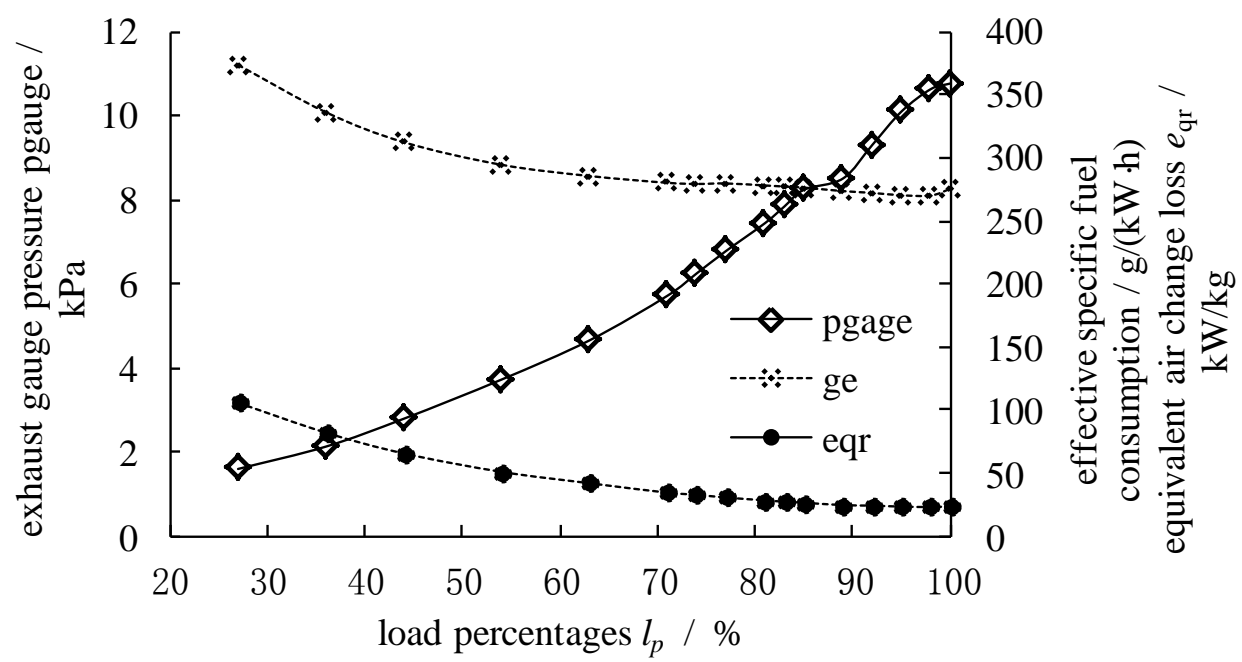

Figure 5: Curve of $e_{q r}, g_{e}$ and $p_{\text {gage }}$ vary with $l_{p}$ under the LJ491QE1 engine $1600 \mathrm{r} / \mathrm{min}$ changing structure small load interval characteristics tests

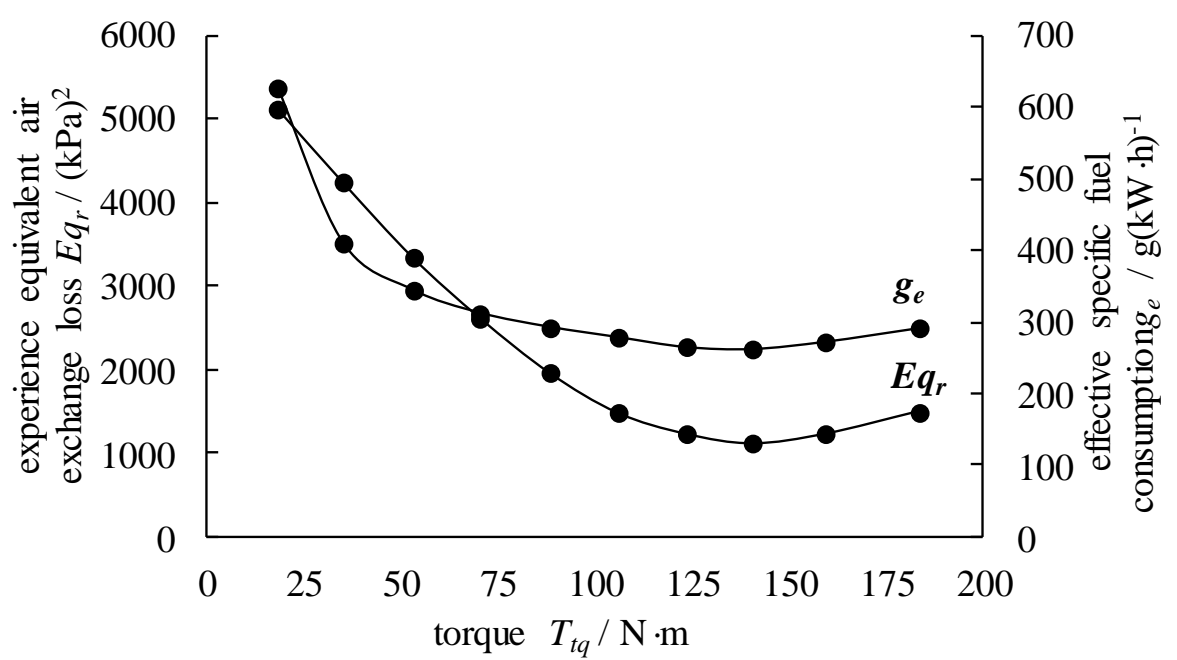

Figure 6: Curves of $E_{q r}$ and $g_{e}$ vary with $T_{t q}$ under the LJ491QE1 engine $3000 \mathrm{r} / \mathrm{min}$ load characteristic tests 


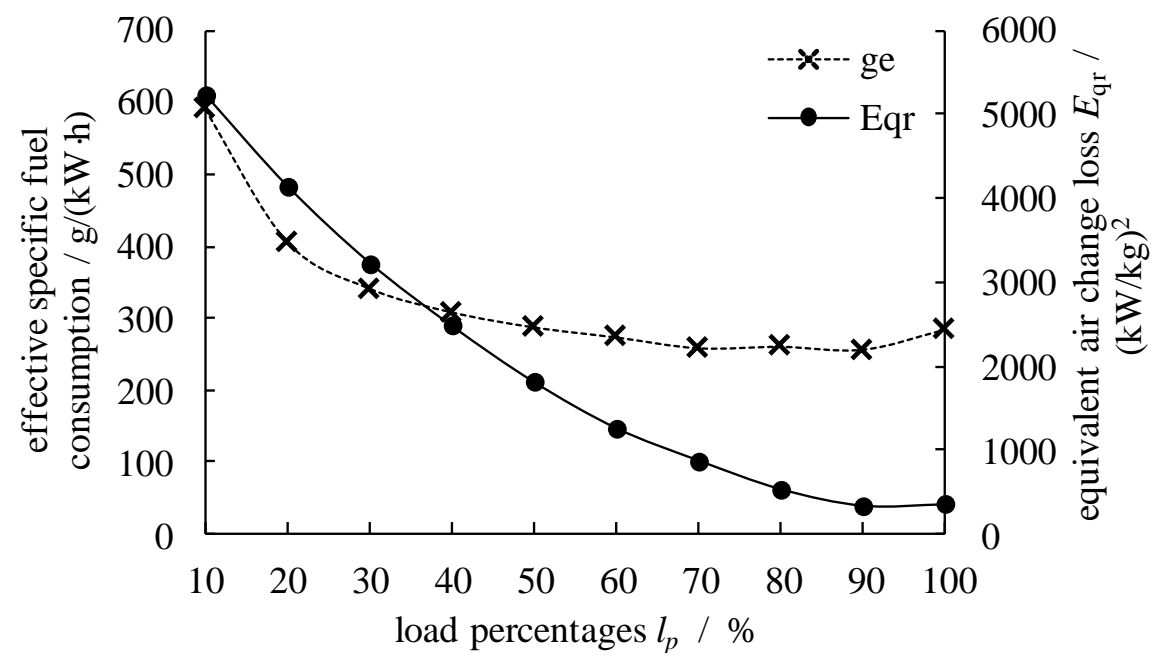

Figure 7: Curve of $E_{q r}$ and $g_{e}$ vary with $l_{p}$ under the 4G18-AA engine $2600 \mathrm{r} / \mathrm{min}$ load characteristic tests

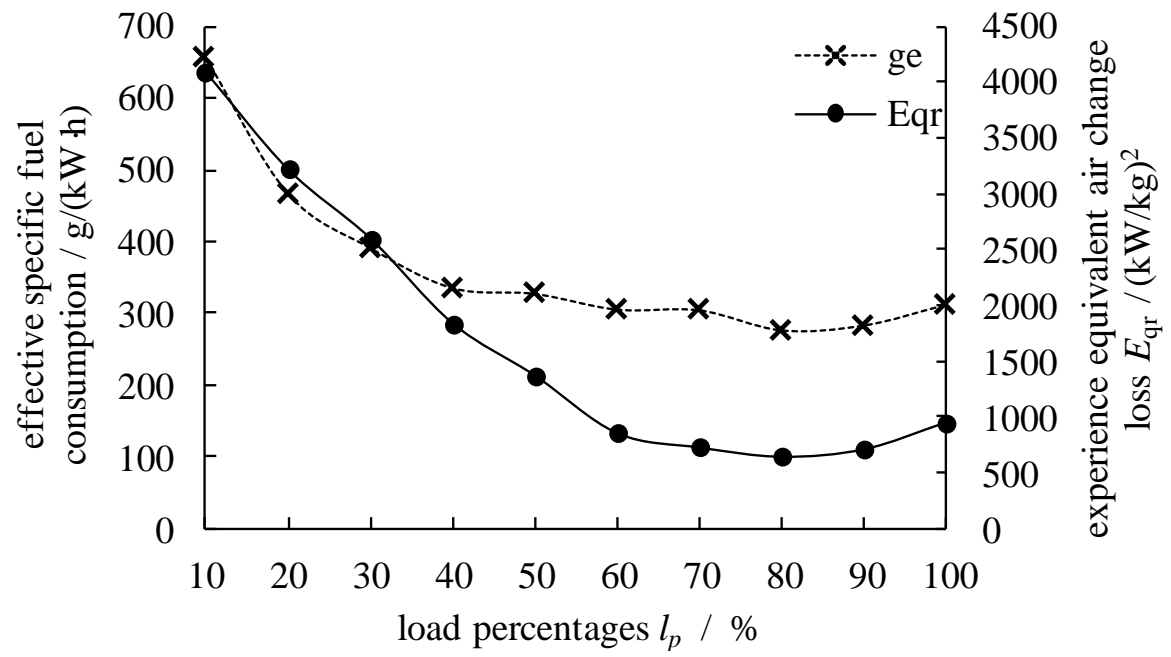

Figure 8: Curve of $E_{q r}$ and $g_{e}$ vary with $l_{p}$ under the 4G18-AA engine $3600 \mathrm{r} / \mathrm{min}$ changing structure load characteristic tests 